\title{
Treatment of pain associated to knee osteoarthritis in the elderly: a ran- domized double-blind clinical trial with lysine clonixinate*
}

\author{
Tratamento da dor associada à osteoartrose de joelho em idosos: um ensaio clínico \\ aleatório e duplamente encoberto com o clonixinato de lisina
}

Fânia Cristina Santos ${ }^{1}$, Polianna Mara Rodrigues de Souza ${ }^{2}$, João Toniolo Neto ${ }^{3}$, Álvaro Nagib Atallah ${ }^{4}$

* Received from the Discipline of Geriatrics and Gerontology (DIGG), Federal University of São Paulo (UNIFESP), São Paulo, SP.

\section{SUMMARY}

BACKGROUND AND OBJECTIVES: Osteoarthritis $(\mathrm{OA})$ is the most common arthropathy and one of the major causes of chronic pain in the elderly population, which may lead to major functional incapacity of these individuals. Aiming at treating pain of elderly patients with knee OA, we have used lysine clonixinate (LC) and have evaluated its effectiveness

METHOD: Randomized, double-blind, placebocontrolled clinical trial with 109 elderly patients with knee OA-related pain. Participants were distributed in two groups: Group LC and Group P (placebo), who received tablets to be used three times a day for 30 days. Evaluations were performed initially, 15 days after and at study completion, as to pain intensity at rest, at initial movement, ambula-

1. Doctor Assistant and Chief Coordinator, Pain and Osteoarticular Service of the Discipline of Geriatrics and Gerontology, Federal University of São Paulo (UNIFESP), São Paulo, SP, Brazil.

2. Assistant Physician and Sub-Coordinator, Pain and Osteoarticular Service of the Discipline of Geriatrics and Gerontology, Federal University of São Paulo (UNIFESP), São Paulo, SP, Brazil.

3. Assistant Doctor Professor, Clinical Research Nucleus of the Discipline of Geriatrics and Gerontology, Federal University of São Paulo (UNIFESP), São Paulo, SP, Brazil.

4. Head Professor, Discipline of Urgency Medicine and Evidence-Based Medicine and Coordinator of the Post-Graduation course in Internal Medicine and Therapy, Federal University of São Paulo (UNIFESP), São Paulo, SP, Brazil.

Correspondence to:

Fânia Cristina Santos, MD / DIGG - UNIFESP

Rua Francisco de Castro, 105 - Vila Clementino 04020-050 São Paulo, SP.

Fone/Fax: (11) 5575-4848

E-mail: faniacs@uol.com.br tion and joint compression; and the need for additional analgesia, morning stiffness; pain-related functional incapacity, adherence, tolerability and global treatment evaluation.

RESULTS: LC has significantly decreased pain at initial movement and ambulation already in the first 15 days, with $30 \%$ decrease in protokinetic pain and $31.6 \%$ in ambulation, but best results were seen after 30 days, when reductions were $42.3 \%$ and $45.5 \%$, respectively. Additional analgesia was significantly lower with LC: $2.6 \%$ and $9.5 \%$ for groups $\mathrm{LC}$ and $\mathrm{P}$, respectively. There were no differences between groups in morning stiffness and functional incapacity. There has been major adherence and tolerability. Global evaluation was favorable to LC, being excellent or good for $50 \%$ of patients.

CONCLUSION: Lysine clonixinate was effective to treat knee OA-related pain in elderly people.

Keywords: Analgesia, Elderly, Knee, Lysine clonixinate, Osteoarthritis.

\section{RESUMO}

JUSTIFICATIVA E OBJETIVOS: A osteoartrose (OA) é a artropatia mais comum e uma das principais causas de dor crônica na população idosa, podendo levar a grande incapacidade funcional nestes indivíduos. Objetivando o tratamento da dor em idosos com OA de joelho utilizou-se o clonixinato de lisina (CL) e avaliou-se a sua efetividade. MÉTODO: Estudo clínico e duplamente encoberto, aleatório e placebo controlado com 109 idosos com dor associada à OA de joelho. Os participantes foram divididos em dois grupos: Grupo CL e P (placebo) que receberam comprimidos para uso três vezes ao dia por 30 dias. Realizadas avaliações iniciais, após 
15 dias e ao final do estudo, quanto à intensidade de dor em repouso, ao movimento inicial, à deambulação e à compressão articular; necessidade de analgesia complementar, rigidez matinal; incapacidade funcional associada à dor, aderência, tolerabilidade e avaliação global do tratamento.

RESULTADOS: O CL reduziu significantemente a dor ao início do movimento e à deambulação já nos primeiros 15 dias, redução de $30 \%$ da dor protocinética e de $31,6 \%$ à deambulação, mas os melhores resultados ocorreram com 30 dias, quando as reduções foram de $42,3 \%$ e $45,5 \%$, protocinética e à deambulação, respectivamente. A analgesia complementar foi significantemente menor com o CL: $2,6 \%$ e $9,5 \%$, grupos CL e P, respectivamente. Não ocorreram diferenças entre os grupos para rigidez matinal e incapacidade funcional. Houve grande aderência e tolerabilidade. A avaliação global foi favorável para o CL, sendo excelente ou boa em 50\%.

CONCLUSÃO: O clonixinato de lisina foi efetivo no tratamento da dor associada à osteoartrite de joelho em idosos.

Descritores: Analgesia, Clonixinato de lisina, Idoso, Joelho, Osteoartrose.

\section{INTRODUCTION}

Increased life expectancy is related to a higher prevalence of chronic health problems and associated functional incapacities, which are natural consequences of population ageing ${ }^{1}$. Among these, there is osteoarthritis (OA), a universal disease with high incidence especially among the elderly. It is the most common arthropathy ${ }^{2}$ and may lead to major incapacity, especially when affecting joints bearing weight, such as knees and hips. Its prevalence increases with age, being observed radiographic OA changes in up to $85 \%$ of people above 75 years of age a $^{2,3}$.

Knee OA is more common than hip OA, its symptoms are in general more severe and it causes major morbidity, especially with regard to pain and functional incapacity which are present in more than $17 \%$ of individuals aged between 65 and 74 years ${ }^{2,3}$. OA therapy has gone through major advances in recent years, but there are still not well-designed clinical trials with enough duration which show important pharmacological effects to change the disease, that is, there are still no drugs proven to be able to prevent, avoid or revert cartilage lesions in humans ${ }^{4}$. So, being impossible to cure OA, decreasing pain and associated functional incapacity becomes the major therapeutic objective.

For many patients, OA pain relief with analgesics such as acetaminophen is comparable to the relief obtained with non-steroid anti-inflammatory drugs (NSAIDs) ${ }^{4,5}$; however in a meta-analysis involving knee OA clinical trials where simple analgesics and NSAIDs were used, it has been observed that analgesia induced by the latter was significantly better ${ }^{7}$. NSAIDs are more widely used in OA with satisfactory response even when there are no inflammatory signs ${ }^{4}$

Lysine clonixinate (LC) is an anti-inflammatory analgesic with chemical origin in the carboxylic acids group and is characterized by having intense central and peripheral analgesic power and lower antiinflammatory action ${ }^{8}$. Its action mechanism is characterized by the reversible inhibition of cycloxygenase, which blocks prostaglandins synthesis, and by the antagonism to prostaglandins ${ }^{8}$. This dual action may explain the relatively weak correlation between prostaglandins synthesis inhibition and the anti-inflammatory power in vivo. A study has shown that LC is a weak cycloxygenase inhibitor and acts especially in blocking cycloxygenase $2^{9}$. Its action on the central nervous system is suggested by the presence of major analgesic effect, similar to opioids. This intense antinociceptive action depends on the presence of inflammatory or hyperalgic process, which is still not very clear. The interaction of LC with central opioid receptors is suggested, although an action mediated by these receptors has not yet been evidenced ${ }^{10}$.

Although the lack of cost-effectiveness studies comparing LC to other NSAIDs, the use of LC in the clinical practice is considered of lower cost as compared to coxibs, which are included as alternative to patients at risk for adverse upper gastrointestinal tract events ${ }^{11}$.

Several studies have evaluated the use of NSAIDs for knee OA, but few have exclusively addressed the elderly population. Unique LC characteristics were shown in several studies ${ }^{11,12}$, such as high analgesic efficacy regardless of the presence of inflammatory or hyperalgic processes, lack of significant adverse effects and low cost.

The major aim of our study was to evaluate LC effectiveness as compared to placebo $(\mathrm{P})$ to treat pain in elderly people with knee OA. 
The potential risk for adverse gastrointestinal and renal effects with the prolonged use of NSAIDs in the elderly population is well known ${ }^{11}$ so the symptomatic treatment of OA using NSAIDs should last for a short period. So, we decided for a 30-day period study. Today it is very important to carry out studies addressing analgesia in the elderly population, especially those involving effective drugs with less undesirable effects, such as cardiovascular events, which are frequently observed with the use of coxibs ${ }^{14}$, drugs with analgesic effects and less gastrointestinal effects, but of limited use for those with increased cardiovascular risk, such as the elderly.

\section{METHOD}

After the Institution's Research Ethics Committee approval (Process 97/23-09), this double-blind, randomized and placebo-controlled study was carried out. Studied sample was obtained from the Service of Osteoarticular Diseases and Pain, Federal University of São Paulo (UNIFESP).

Participated in the study 109 elderly patients with knee OA-related pain. Inclusion criteria were age equal to or above 60 years; both genders and any ethnical group; diagnosis of idiopathic knee OA (femorotibial compartment), with at least one affected knee, clinically and radiologically confirmed by the American College of Rheumathology (ACR) criteria $^{3}$; pain in the knee (for at least 3 months) at rest or moving, with intensity equal to or above 30 $\mathrm{mm}$ in the pain visual analog scale (VAS) ${ }^{8}$; lack of diseases which could change the follow-up of the study; understanding and motivation, in the investigator's opinion, to complete the study, free and informed signed consent, according to clinical research best practices.

Exclusion criteria were history of allergy or intolerance to LC or other NSAIDs; history or presence of peptic ulcers in the last 12 months; history of gastrointestinal hemorrhage; kidney or liver disease, or even intestinal inflammatory disease; connective tissue disease. Psoriasis or porphyry; current alcoholism history; use of NSAIDs in the last seven days; meniscopathies, concomitant bursitis or tendonitis; use of steroids by any route in the last 2 months; use of anticoagulants; inflammatory, infectious, microcrystalline, metabolic and hematological diseases, arthropathies by avascu- lar and tumor necrosis; obesity with body mass index (BMI) higher than 40; severe uncontrolled chronic diseases (hypertension, diabetes mellitus, heart disease and other diseases which, by their nature or proposed treatment, could interfere, in the investigator's opinion, with the proposed evaluation); presence of important joint deviation in the affected knee and / or with surgical indication; presence of thigh arthritis or ankle or foot arthritis. Initial evaluation followed the sequence below: 1. Clinical observation and confirmation of knee OA diagnosis. 2. Signature of the Free and Informed Consent Term (FECT). 3 Knee pain intensity evaluation. 4. Evaluation of morning joint stiffness. 5. Evaluation of pain-related functional incapacity. 6. Randomization and 7. Delivery of drugs and instructions about their use, as well as the use of additional analgesia.

VAS was used for different situations to evaluate knee pain intensity: pain at rest, at initial movement, at ambulation and at joint compression.

Morning joint stiffness was measured by its duration, being used a 4 -point scale: $0=1$ ess than one minute, $1=$ from one to 15 minutes, $2=16$ to 30 minutes, $3=$ more than 30 minutes. For pain-related functional incapacity patients were asked whether knee pain was associated to any impairment in daily activities (DA), following the questions of the "Older American Resources and Services - OARS - Methodology"16 for functional incapacity in the elderly. Then, functional incapacity was classified in: Class 1: pain did not cause any damage to DA, Class 2: pain caused damage to few DA (two activities), Class 3: pain caused severe damage to DA (three activities), Class 4: pain caused severe incapacity for DA (four or more activities).

Groups were randomly formed. Participants received a bottle with 90 tablets with $125 \mathrm{mg} \mathrm{LC}$ or $\mathrm{P}$ and were instructed about oral administration every eight hours for 30 days. They were also instructed to use additional analgesia being allowed oral analgesia with dipirone or acetaminophen, if needed. They were not allowed throughout the study to use NSAIDs, steroids, myorelaxants, opioids, phytotherapeutic drugs or local treatment with analgesics.

Two control evaluations were made at 15 days interval (visit 2 and visit 3), for clinical exams and pain, joint stiffness, pain-related incapacity reevaluations and to check the need for additional an- 
algesia. Adhesion to treatment and tolerability were also checked.

LC analgesic effectiveness was established according to the following parameters: improved pain at rest, at initial movement, at ambulation, at joint compression and the need for additional analgesia.

For adhesion to treatment we asked about the use of the drugs in prescribed doses and forms. At the end of the study, bottles still with tablets were counted and remaining tablets were recorded. Adhesion to treatment was considered good when there was no treatment interruption. When patients did not show up for the control evaluations, all efforts were made to contact them and find out the reasons for the absence: lack of efficacy, adverse events or even other reasons.

To evaluate tolerability, clinical adverse events were asked, followed by a structured questionnaire: presence of pyrosis, heartburn, nausea, vomiting, epigastric pain, intestinal bleeding, hematemesis, epigastric plenitude, diarrhea, headache and dizziness. If present, their intensity was recorded (mild, moderate or severe). Adverse clinical events were also spontaneously reported.

The investigator gave his opinion about the global treatment evaluation at the end of the study. This evaluation was classified as: very bad, bad, regular, good or excellent treatment.

Pearson's Chi-square, Student's $t$ and Wald tests were used for statistical analysis of results. In all cases, rejection level for null hypothesis was always established as lower than or equal to $0.05(5 \%)$.

\section{RESULTS}

Study sample was composed of 109 elderly patients, 63 in LC group and 46 in P group. From these, 12 have not completed the study, 5 in LC group and 7 in $\mathrm{P}$ group (reasons were unwillingness to continue the study).

Mean age was 72 years for LC group and 73 years for P group, without statistically significant difference between groups. Most were females (88.1\%); $96.3 \%$ in LC groups and $80.4 \%$ in $\mathrm{P}$ group. Few males participated in the study and, in spite of the significant difference in this data $(p=0.042)$, this was not relevant for statistical analysis. As to race, $82.5 \%$ were Caucasians, $14.5 \%$ were Blacks and $2.8 \%$ were Yellow, without statistical difference between groups $(\mathrm{p}=0.911)$.

As to pain intensity in different situations, means in the beginning of the study were: $6.7 \mathrm{~mm}$ at rest for LC group and $8.9 \mathrm{~mm}$ for $\mathrm{P}$ group, $83 \mathrm{~mm}$ at initial movement for LC group and $78.5 \mathrm{~mm}$ for P group; 74.1 at ambulation for LC group and $70.9 \mathrm{~mm}$ for $\mathrm{P}$ group and $35.4 \mathrm{~m}$ at joint compression for LC group and 35.9 for P group (Table 1). There were no significant differences between groups in this parameter, except for pain at ambulation, which was higher in LC group ( $p=0.049)$.

Morning stiffness was not present in $52 . \%$ and $32.6 \%$ of LC and $\mathrm{P}$ groups, respectively, and when present it was brief, that is, pain lasting for 1 to 15 minutes $(36.5 \%$ in LC groups and $54.4 \%$ in P group, $\mathrm{p}=0.081)$.

As to pain-related incapacity, most patients pre-

Table 1 - Characterization of the sample according to pain intensity in different situations and according to pain-related incapacity

\begin{tabular}{|c|c|c|c|c|c|}
\hline \multirow[t]{2}{*}{ Groups } & \multicolumn{3}{|c|}{ Pain Intensity (mm) } & \multirow[b]{2}{*}{$\begin{array}{c}\text { Ambulation } \\
\text { (mean) }\end{array}$} & \multirow[b]{2}{*}{$\begin{array}{c}\text { Compression } \\
\text { (mean) }\end{array}$} \\
\hline & $\begin{array}{c}\text { Rest } \\
\text { (mean) }\end{array}$ & $\begin{array}{c}\text { Initial Mov. } \\
\text { (mean) }\end{array}$ & & & \\
\hline$\overline{\mathrm{LC}}$ & 6.7 & 83.0 & & 74.1 & 35.4 \\
\hline Total & 7.8 & 80.7 & & 72.5 & 35.6 \\
\hline $\mathrm{p}$ Value & 0.079 & 0,163 & & 0.049 & 0.456 \\
\hline & $\mathrm{n}(\%)$ & $\mathrm{n}(\%)$ & $\mathrm{n}(\%)$ & $\mathrm{n}(\%)$ & $\mathrm{n}(\%)$ \\
\hline$\overline{\mathrm{LC}}$ & $19(30.2)$ & $28(44.4)$ & $14(22.2)$ & $2(3.2)$ & $63(100)$ \\
\hline $\mathrm{P}$ & $17(36.7)$ & $19(41.3)$ & $9(19.6)$ & $1(2.2)$ & $46(100)$ \\
\hline Total & $36(33.0)$ & $47(43.1)$ & $23(21.1)$ & $3(2.8)$ & $109(100)$ \\
\hline
\end{tabular}

$\mathrm{p}$ Value $=0.786$

$1=$ pain does not cause any incapacity; 2 = pain causes minor incapacity (impairment of 2 DA); 3 = pain causes considerable incapacity (impairment of $3 \mathrm{DA}$ ); 4 = pain causes major incapacity (impairment of 4 or more DA). 


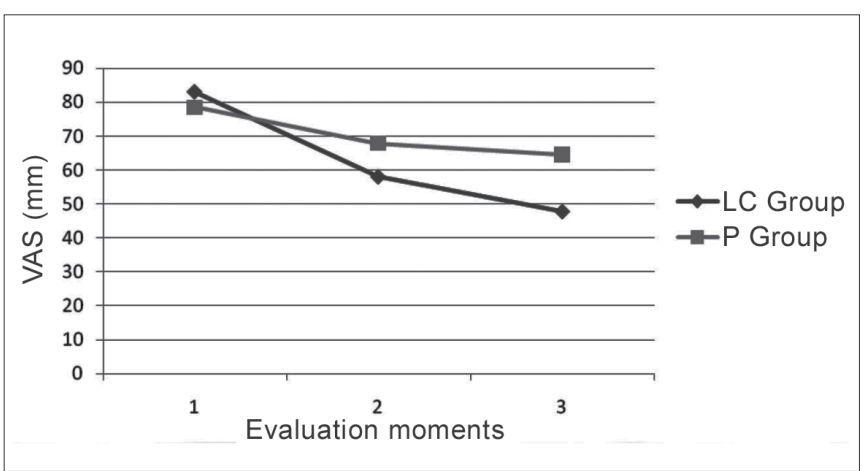

Graph 1 - Pain means at initial movement along the study, according to each studied group.

Wald test: interaction between groups; $p=0,001$

Pain decrease Group LC Group P

(visit $1 \mathrm{x}$ visit 2) $\mathrm{p}<0.001 \mathrm{p}=0.006$

(visit $1 \mathrm{x}$ visit 3 ) $\mathrm{p}<0.001 \mathrm{p}<0.001$

(visit $2 \mathrm{x}$ visit 3 ) $\mathrm{p}<0.001 \mathrm{p}=0.287$

sented mild incapacity $(44.4 \%$ in LC group and $41.3 \%$ in $\mathrm{P}$ group, $\mathrm{p}=0.786$ ) (Table 1$)$.

About LC analgesic effectiveness, it was not more effective than $P$ to decrease pain at rest $(p=0.079)$, but for pain at initial movement, groups had different behaviors along the study ("interaction effect" between time and groups in statistical language) (Graph 1). With LC, this pain decreased in average $30 \%$ in the first 15 days, with statistically significant difference $(\mathrm{p}<0.001)$ and $12.3 \%$ more from there on, also with significant decrease $(p<$ $0.001)$. P group had significant decrease of $13.5 \%$ only in the first 15 days $(p=0.006)$, but then it remained unchanged $(p=0.287)$. There has been an "interaction effect" because behavior of groups has changed, that is, along time groups have "changed position" and the LC group started to show a lower pain mean as compared to P group $(\mathrm{p}=0.001)$.

The same was true with pain at ambulation, as shown in graph 2 . Here we have also observed different behaviors of groups, that is, there has been also the "interaction effect". It has been observed that the LC group has significantly decreased pain at ambulation in $31.6 \%$ in the first 15 days ( $p<$ 0.001 ) and $13.9 \%$ more from this point until the end of the study $(\mathrm{p}=0.002)$. There has been a significant decrease of $12.8 \%$ in $\mathrm{P}$ group during the first 15 days $(p=0.009)$ but then it has not been further decreased $(p=0.951)$. So, according to the "interaction effect" LC was more effective than P for pain at ambulation analgesia.

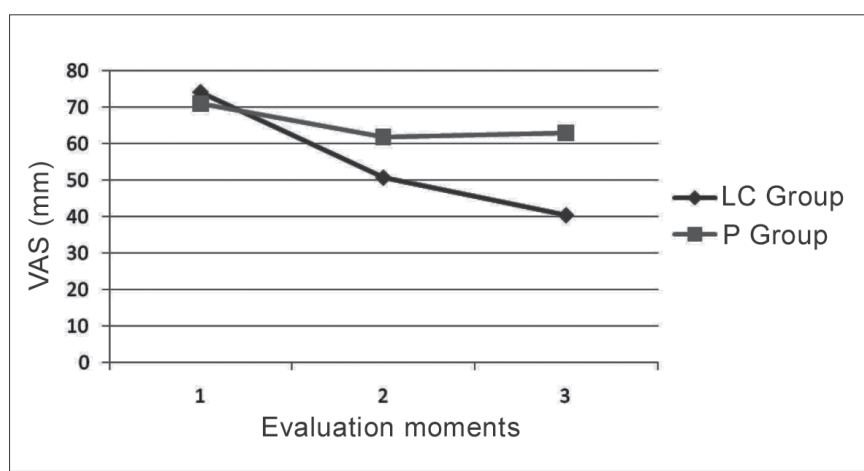

Graph 2 - Pain means at ambulation along visits, according to each studied group.

Wald Test: interaction between groups; $\mathrm{p}<001$

Pain decrease Group LC Group P

(visit $1 \mathrm{x}$ visit 2) $\mathrm{p}<0.001 \mathrm{p}=0.009$

(visit $1 \mathrm{x}$ visit 3 ) $\mathrm{p}<0.001 \mathrm{p}<0.027$

(visit $2 \mathrm{x}$ visit 3 ) $\mathrm{p}=0.002 \mathrm{p}=0.951$

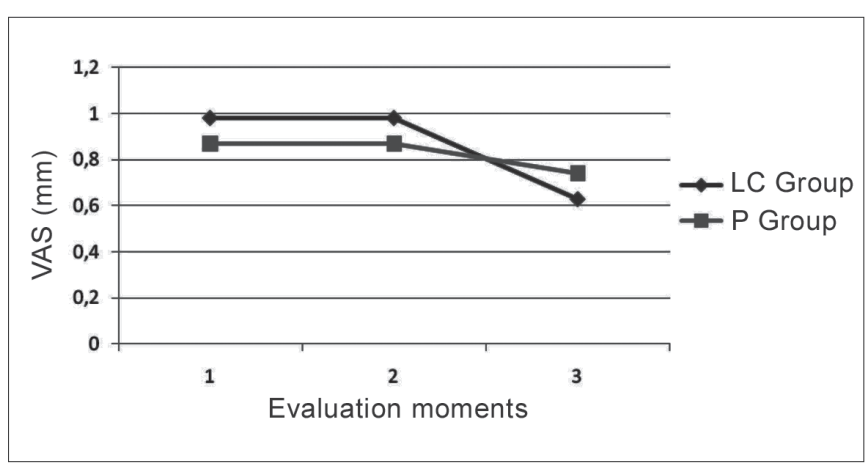

Graph 3 - Means of pain-related incapacity along the study, according to each studied group.

Wald Test: pain-related incapacity; $\mathrm{p}=0,786$

Groups LC and P:

(visit $1 \mathrm{x}$ visit 2) $\mathrm{p}=0.317$

(visit $1 \mathrm{x}$ visit 3) $\mathrm{p}<0.001$

(visit $2 \mathrm{x}$ visit 3) $\mathrm{p}<0.001$

As to joint compression, groups had the same behavior along the treatment $(\mathrm{p}=0.456)$. The same was true for morning joint stiffness, that is, LC was not more effective to decrease morning stiffness ( $p$ $=0.081)$.

As to additional analgesia, $26.1 \%$ of $\mathrm{P}$ group has received it as compared to only $9.5 \%$ of LC group with statistically significant difference $(\mathrm{p}=0.021)$. In terms of pain-related functional incapacity, there has been no change in both groups, that is, there were no different behaviors along the study between groups $(p=0.786)($ Graph 3$)$. 
In global treatment evaluation there has been statistically significant difference between groups, with a significantly more favorable evaluation for LC, being that $50 \%$ of such group had global evaluation classified as good or excellent, while only $21.1 \%$ of $P$ group had the same evaluation $(p=0.010)$. And more, $\mathrm{P}$ group had more global evaluations classified as very bad or bad ( $57.9 \%$ P versus $34.5 \%$ LC). All patients who completed the study used the drug correctly so the adhesion to treatment was considered very good.

There were $37.9 \%$ adverse reactions in LC group as compared to $23 \%$ in $\mathrm{P}$ group, without significant differences between groups $(p=0.124)$. Major reactions were: epigastric pain, heartburn, pyrosis, nausea, dizziness, headache, lower limbs edema, pruritus and sleepiness. Reactions were mainly of mild to moderate intensity. There was one case of mild melena. There has been no treatment interruption by adverse events and also no hospitalization.

\section{DISCUSSION}

This study aimed at contributing to further knowledge about the effects of LC, which is a drug with high analgesic potential and good tolerability for elderly patients with knee OA-related pain. This is the first study using LC exclusively in the elderly population.

With regard to demographics, mean age was not very high: 72 years for LC group and 73 years for $\mathrm{P}$ group. There were more females and clear predominance of Caucasians, but the sample was homogeneous when comparing groups.

Still trying to characterize the sample, most severe pain associated to knee OA in different situations were protokinetic and ambulating pain. The presence of severe pain in these situations is a very important problem for the elderly, because it is known that pain at initial movement or at ambulation may predispose to falls by impairing balance ${ }^{17}$.

Most patients in both groups had no morning stiffness or had it very briefly, so joint stiffness did not significantly impact the study. The same was true for pain-related functional incapacity because major incapacities were only seen in a small percentage of individuals. That is, the most disabling form associated to pain was observed in only $2.75 \%$ of the elderly, and the considerable incapacity (impairment of 3 DA) was present in $21.1 \%$ of cases. The tool used to evaluate pain-related incapacity was very practical to apply, but could pose some methodological problem. There was agreement among authors who have also used it $^{16}$ that the tool could not have been validated for joint pain purposes.

In this clinical trial, LC was more effective in decreasing pain at initial movement and at ambulation: $42.3 \%$ decrease in protokinetic pain $(\mathrm{p}<$ $0.001)$ and $45.5 \%$ at ambulation $(\mathrm{p}=0.002)$. A significant improvement of this pain was already observed during the first 15 days of treatment, but best results were seen at the end of 30 days. So, an important data for symptomatic treatment of elderly people with pain associated to knee OA, would be the use of LC for 30 days to have an optimized analgesia. In addition, protokinetic or at ambulation pain relief could bring major benefits for the elderly, including less falls ${ }^{17}$.

LC was not more effective in decreasing pain at rest because both groups presented the same behavior along the study. The same was true for joint compression pain. But for these two situations of OA pain, mean intensities were low in the beginning of the study (VAS of $6.7 \mathrm{~mm}$ and $8.9 \mathrm{~mm}$ at rest for LC and P groups, respectively, and VAS of 35.4 $\mathrm{mm}$ and $35.9 \mathrm{~mm}$ at joint compression for LC and $\mathrm{P}$ groups, respectively) and this could have influenced results.

In our study there has been less analgesic complementation to patients using LC $(p=0.021)$ and this could also represent a better analgesic action of such drug.

According to Fisher et al. ${ }^{18}$ there are fast onset analgesics, however with a therapeutic effect which may not be persistent. These agents, according to the same author, are the most widely used to treat symptomatic knee OA. Among major drugs used in the elderly with symptomatic knee OA there are dipirone acetaminophen and NSAIDs, however the latter are associated to major adverse events risk in such population, even when used for a short period $^{19}$.

Some studies have shown that the clinical efficacy of NSAIDs in equipotent doses is similar. However the individual response is highly variable ${ }^{20}$. Variability of responses to NSAIDs in OA cannot be explained by the severity of the disease and the mechanism involved in these responses is not totally explained ${ }^{20}$. The better understanding of the effectiveness of different existing NSAIDs 
used in different populations with knee OA-related pain is of great importance because this way we could have more treatment options depending on patients' profile.

Short clinical trial have shown that newest NSAIDs, especially coxibs, are effective for knee OA analgesia and have good tolerability, but these have not yet been addressed exclusively to the elderly population $^{21,22}$.

In a clinical trial with 3294 Brazilians with symptomatic knee $\mathrm{OA}^{23}, 49 \%$ of individuals showed major pain improvement (at rest, initial movement, ambulation and joint compression) with the use of aceclofenac. However, this was not a controlled and randomized study and has not dealt exclusively with the elderly population.

Pain-related functional capacity did not improve in our study. Since it was a functionality evaluated for a very short period, it was to be expected that such functional improvement could not have occurred. In a functionality evaluation in the elderly using the OARS Methodology ${ }^{16}$, demonstrations of pain improvement could favorably reflect in the global individual functionality, and the same has not been shown here in a statistically significant way. So, a limitation of the study could be the functionality approach for a treatment for such a short period. In addition, more specific tools were not used, such as WOMAC (Western Ontario and McMaster Universities Osteoarthritis) Index, which has been used in clinical trials involving OA in the general population ${ }^{24}$.

There has been no significant improvement in morning stiffness with LC and this result is different from those found by some researchers with regard to knee OA. Eberhardt ${ }^{12}$ has shown that LC has significantly improved morning stiffness, but measurement was of stiffness intensity and not of its duration as it is our case. Since the beginning of the study, morning stiffness was not a frequent finding in its more severe form, that is, it has not frequently been presented with prolonged duration.

So, changes could not have been detected in a so infrequent finding. Global treatment evaluation was more favorable for patients receiving $\mathrm{LC}$ and this could be one more reflex of the higher LC analgesic effectiveness for knee OA in the elderly.

Treatment adhesion was considered very good and this is important because the difficult adherence to NSAIDs is known, especially in the elderly. When a high adhesion to a drug treatment is not achieved, it is inferred that it has not been effective, or even has caused major adverse reaction to the point of impairing adhesion.

LC tolerability criteria were similar to $\mathrm{P}(37.9 \%$ frequency of adverse events in LC group and $23.1 \%$ in the placebo group; $p=0.124)$. In spite of the reasonable presence of undesirable effects with LC, most in the gastrointestinal tract, they were mild with no need for any specific treatment, especially with no need for any intervention (transient events with spontaneous resolution). Such results ratify the low incidence of adverse effects with $\mathrm{LC}^{12}$. A systematic review involving 16 clinical trials with different NSAIDs, reported a relative risk of 2.74 (Confidence Interval (CI) 95\%; 2.54-2.97) for any gastrointestinal complication with NSAIDs ${ }^{11}$. In this same review addressing elderly people aged 65 years or more, the risk increased to 5.52 (CI 95\%; 4,63-6.60). A study on hospitalization caused by drug adverse reactions in the elderly aged 65 years or more has pointed NSAIDs as responsible for $23.5 \%$ of cases $^{25}$. This way, we see how important it is that new drugs are studied in the elderly population, and that they do not increase the risks of complications, such as the hospitalization risk.

Other limitation of our study was the small sample size, however we were able to show differences between treatments. In the elderly with knee OArelated pain, LC was effective, that is, decreased protokinetic and ambulation pain and has led to a lower consumption of additional analgesics. In addition, LC treatment was globally considered good or excellent.

\section{CONCLUSION}

LC was effective for the elderly with OA-related pain in relieving protokinetic and ambulation pain for a period of 15 days, and when used for 30 days, analgesia was optimized. Also a lower consumption of additional analgesics was observed with LC and global evaluation of LC treatment by the investigator was good or excellent. LC tolerability profile was highly reasonable for the elderly (lack of severe adverse events) and there has been major adherence to treatment.

We advocate the need for new clinical trials in Brazil involving the elderly with chronic pain, such as 
those with knee $\mathrm{OA}$, and also that other effective analgesic drugs for such prevalent and disabling disease in the elderly are evaluated. This clinical trial with elderly people may contribute to metaanalysis and systematic reviews involving gonarthrosis, because increasingly there is the need to carry out new randomized clinical trials addressing different populations.

\section{REFERENCES}

1. Ramos LR, Toniolo J, Cendoroglo MS, et al. Two-year follow-up study of elderly residents in S. Paulo, Brazil: methodology and preliminary results. Rev Saude Publica 1998;32(5):397-407.

2. Felson DT. Epidemiology of hip and knee osteoarthritis. Epidemiol Rev 1998;10(1):1-28.

3. Altman R, Asch E, Bloch D, et al. Development of criteria for the classification and reporting of osteoarthritis. Classification of osteoarthritis of the knee. Arthritis Rheum 1986;29(8):1039-49.

4. Zhang W, Moskowitz RW, Nuki G, et al. OARSI recommendations for the management of hip and knee osteoarthritis, Part II: OARSI evidence-based, expert consensus guidelines. Osteoarthritis Cartilage 2008;16(2):137-62.

5. Bradley JD, Brandt KD, Katz BP, et al. Comparison of an anti-inflammatory dose of ibuprofen, an analgesic dose of ibuprofen and acetaminophen in treatment of patients with osteoarthritis of the knee. N Engl J Med 1991;325(2):87-91.

6. Zhang W, Jones A, Doherty M. Does paracetamol (acetaminophen) reduce the pain of osteoarthritis? A metaanalysis of randomised controlled trials. Ann Rheum Dis 2004;63(8):901-7.

7. Lee C, Straus WL, Balshaw R, et al. A comparison of the efficacy and safety of nonsteroidal antiinflammatory agents versus acetaminophen in the treatment of osteoarthritis: a meta-analysis. Arthritis Rheum 2004;51(5):746-54.

8. Bird RA, Simonetti MPB. Avaliação das atividades analgésica e antiinflamatória do clonixinato de lisina; estudo experimental em ratos. Rev Dor 2000;2(1):7-12.

9. Franchi A, di Girolamo G, de los Santos AR, et al. Effects of lysine clonixinate and indomethacin on the lipoxigenase and ciclooxigenase activity of colon isolated from cancer patients. Medicina (B. Aires) 1998;58(3):291-4.

10. Ortí E. Evidence for NSAIDs with the central opioid receptor system. APPTLA 1996;46(3):199.

11. García-Rodrígues LA. Nonsteroidal antiinfl ammatory drugs, ulcers and risk: A colaborative meta-analise. Semin Arthritis Rheum 1997;26(Suppl 1):16-20.

12. Eberhardt H. Analgesic Effi cacy and tolerability of lysine clonixinate versus ibuprofen in patients with gonarthrosis. Current Therap Res 1995;56(6):573-80.

13. Kirchner JT. Nonsteroidal anti-infl ammatory drug use in the elderly: issues of compliance and safety. J Am Osteopath Assoc 1994;94(4):300-04.

14. McGettigan P, Henry D. Cardiovascular risk and inhibition of cyclooxygenase: a systematic review of the observational studies of selective and nonselective inhibitors of cyclooxygenase 2. JAMA 2006;296(13):1633-44.

15. Price DD, McGrath PA, Rafi i A, et al. The validation of visual analogue scales as ratio scale measures for chronic and experimental pain. Pain 1983;17(1):45-56.

16. George LK, Fillenbaum GG. OARS methodology. A decade of experience in geriatric assessment. J Am Geriatr Soc 1985;33(9):607-15.

17. Sudarsky L. Geriatrics: gait disorders in the elderly. N Engl J Med 1990;322(2):1441-6.

18. Fisher NM, Kame VD Jr, Rouse L, et al. Quantitative evaluation of a home exercise program on muscle and functional capacity of patients with osteoarthritis. Am J Phys Med Rehabil 1994;73(6):413-20.

19. AGS - Panel on pharmacological management of persistent pain in older. J Am Geriatr Soc 2009;57(8):1331-46.

20. Furst DE. Are there differences among nonsteroidal antiinflammatory drugs? Comparing acetylated salicylates, nonacetylated salicylates, and nonacetylated nonsteroidal antiinflammatory drugs. Arthritis Rheum 1994;37(1):1-9.

21. Leung AT, Malmstrom K, Gallacher AE, et al. Efficacy and tolerability profi le of etoricoxib in patients with osteoarthritis: A randomized, double-blind, $\mathrm{P}$ and active-comparator controlled 12-week effi cacy trial. Curr Med Res Opin 2002;18(2):49-58.

22. Kivitz A, Eisen G, Zhao WW, et al. Randomized placebo-controlled trial comparing efficacy and safety of valdecoxib with naproxen in patients with osteoarthritis. J Fam Pract 2002;51(6):530-37. 
23. Lederman R. Tratamento de 3294 pacientes com osteoartrose usando a mesma medicação: estudo multicêntrico: epidemiológico e evolutivo. Arq Bras Med 1997;71(2):73-8.

24. Bellamy N. Outcome measurement in osteoarthritis clinical trials. J Rheumatol 1995;22:(Supp1 43):49-51.
25. Franceschi M, Scarcelli C, Niro V, et al. Prevalence, clinical features and avoidability of adverse drug reactions as cause of admission to a geriatric unit: a prospective study of 1756 patients. Drug Saf 2008;31(6):545-56.

Presented in November 17, 2010.

Accepted for publication in Februray 28, 2011. 